\title{
Organic geochemical studies of soils from the Rothamsted Classical Experiments-IV. Preliminary results from a study of the effect of soil pH on organic matter decay
}

\author{
PIM F. VAN BERGEN*1, CHRIS J. NOTT'1 IAN D. BULL ${ }^{1}$, PAUL \\ R. POULTON ${ }^{2}$ and RICHARD P. EVERSHED ${ }^{1 \dagger}$ \\ 'Organic Geochemistry Unit, School of Chemistry, University of Bristol, Cantock's Close, Bristol BS8
}

1TS, U.K. and ${ }^{2}$ Soil Science Department, IACR-Rothamsted, Harpenden, Herts AL5 2JQ, U.K.

\begin{abstract}
Total lipid extracts and solvent insoluble organic matter in soils from the Park Grass Experiment at Rothamsted Experimental Station, Harpenden, U.K. were studied to determine the effect of $\mathrm{pH}$ on the preservation/degradation of plant derived biomolecules. Analyses involved high temperaturegas chromatography (HT-GC), HT-GC-mass spectrometry (HT-GC-MS), GC combustion-isotope ratio MS (GCC-IRMS) and flash pyrolysis-GC (Py-GC) and Py-GC-MS. The plots selected for study have $\mathrm{pH}$ values ranging from 3.7 to 7.3 , with acidic soils exhibiting two distinct horizons (i.e. humic rich top layer and mineral soil). The total lipid extracts of the soil samples with low pH exhibited higher relative abundances of long-chain $\left(>\mathrm{C}_{20}\right)$ organic acids believed to be derived largely from oxidation of plant lipids. The vegetation signature in the low molecular weight fraction is only retained in the humic rich top layer. The signal in the mineral layer is believed to derive primarily from previous vegetation. Compound specific stable carbon isotope $\left(\delta^{13} \mathrm{C}\right)$ measurements of long-chain $n$-alkanols are considered to reflect differences in the rate of incorporation of plant lipids into the humic top layer related to the grass species dominating the standing vegetation. In the soil samples of low $\mathrm{pH}$, lignin contributes to the high molecular weight fraction of the humic layer. In contrast, the mineral layer of the same soil shows little evidence of intact lignin, but is instead dominated by amino acid pyrolysis products, probably deriving from (degraded) polypeptides. The pyrolysates of the mineral soils of high $\mathrm{pH}$ yield a distribution of products similar to that found in the deeper layer of the low $\mathrm{pH}$ samples but with evidence of lignin derived moieties. Overall, soil $\mathrm{pH}$ was found to have a significant effect on the preservation of higher plant derived biomolecules including ligno-cellulose. (C) 1998 Elsevier Science Ltd. All rights reserved
\end{abstract}

Key words - Rothamsted Classical Experiment, soil organic matter, lipids, Park Grass, soil pH, gas chromatography, mass spectrometry, stable carbon isotopes, flash pyrolysis

\section{INTRODUCTION}

Soil organic matter (SOM) is one of the major carbon pools in the biosphere (Post et al., 1982). Globally there is substantially more carbon in the top metre of soil than in the overlying vegetation or in the atmosphere. Soil organic matter is composed of plant, animal and microbial residues, at varying stages of decomposition, and amorphous humic substances. Humification and mineralisation processes are responsible for changing the chemical composition of soil organic matter and are of great importance to the terrestrial carbon cycle (e.g. Oades, 1988; Jenkinson et al., 1992; Paul and Clark, 1996; Kögel-Knabner, 1992 and references cited therein). The size of the soil organic matter reservoir depends upon plant growth and the extent

*Present address: Organic Geochemistry Group, Geochemistry, Faculty of Earth Sciences, Utrecht University, P.O. Box 80021, 3508 TA Utrecht, Netherlands.

$\dagger$ To whom correspondence should be addressed. Fax: $+44-117-929-3746$. and rate of mineralization of the plant residues entering the soil (Coûteaux et al., 1995). This in turn is controlled by several factors including soil type, climate, biochemical composition of the plant residue and the nature and abundance of decomposing organisms. Soil $\mathrm{pH}$ also has a profound effect on soil organic matter preservation and decomposition, although its precise mode of influence has yet to be fully established (Motavalli et al., 1995).

There are many conflicting views concerning the relationship between soil $\mathrm{pH}$ and soil organic matter. Hardon (1936) found that in acidic soils organic carbon contents increased and Spain (1990) also observed a negative correlation between soil organic matter and soil $\mathrm{pH}$ in tropical rainforest soils. Several researchers have found an increase in $\mathrm{C}$ mineralisation after soils have been limed or reductions in carbon mineralisation after acidification (Motavalli et al., 1995). In contrast, Oades (1988) predicted shorter $\mathrm{C}$ turnover times in acidic soils compared with calcareous soils. Amblès et al. (1989) found no additional decomposition of soil 
monoacids with increased soil $\mathrm{pH}$, instead they observed a transfer of monoacids, diacids, ketoacids and hydroxyacids from the unbound to the bound phase. Furthermore, they attributed the accumulation of fatty acids in acidic soils to the lack of Fehydroxide, or specific clay minerals rather than to acidity per se.

Previous studies at Rothamsted Experimental Station have revealed a significant difference in lignin-cellulose contribution to soils from two Wilderness sites, Broadbalk and Geescroft Wilderness (van Bergen et al., 1997a, 1998). The only major difference between the sites was the soil $\mathrm{pH}$ (7.1 and 4.2, respectively). Based on these observations we suggested that the absence of lignocellulose in the soil at the Broadbalk Wilderness site was closely linked to the alkaline nature of this soil (van Bergen et al., 1997a). Guggenberger et al. (1994, 1995) also observed a significant lignin contribution in soils with a $\mathrm{pH}<5$, whereas soils with $\mathrm{pH}>5$ showed little evidence of lignin. Motavalli et al. (1995) also suggested that acidic soil reduces the decomposition rates of freshly added organic materials.

In this paper we studied solvent soluble and insoluble fractions of soil organic matter using soils from several plots of the Park Grass Experiment to determine the effect of soil $\mathrm{pH}$ on the organic matter composition. The Park Grass Experiment is the oldest and best documented grassland experiment in the world. Vegetation samples were examined in parallel with the underlying soils in an effort to follow the fate of the major plant components in soil. Total lipid extracts (TLEs) were studied using high temperature gas chromatography-mass spectrometry (HT-GC-MS), whilst flash pyrolysis-gas chromatography-mass spectrometry (Py-GC-MS) was used to investigate the insoluble fraction. Additionally, several TLEs were fractionated to obtain an alkanol fraction which was studied using gas chromatography combustion isotope ratio mass spectrometry (GCC-IRMS).

\section{SAMPLE DESCRIPTION}

\section{Park Grass Experiment}

The Park Grass Experiment is located on an area of grassland at Rothamsted Experimental Station, Harpenden, Herts. U.K. The experiment was laid down in 1856, the field being under pasture for at least a century before this (Tilman et al., 1994). Control plots show the characteristic mixed plant population of old grassland. The boundaries of the plots are clearly defined with the transition between adjacent treatments occupying $30 \mathrm{~cm}$ or less. This indicates little sideways movement of nutrients in flat undisturbed soil. At the start of the experiment, the site had received no regular dressings of calcium carbonate and the $\mathrm{pH}$ was in the region of 5.7. A test of liming began in 1903, was modified in 1965 , and the plots now range in $\mathrm{pH}$ from 7.3-3.5, depending on treatment (Johnston et al., 1986).

The soil is a Stagnogleyic paleo-argillic brown earth, classified as Chromic Luvisol (F.A.O., 1990) or Aquic Paleudalf (U.S.D.A., 1992). The mechanical composition of the soil is approximately $19 \%$ sand $(60 \mu \mathrm{m}-2 \mathrm{~mm}), 58 \%$ silt $(2-60 \mu \mathrm{m})$ and $23 \%$ clay $(<2 \mu \mathrm{m})$ (Avery and Catt, 1995). The clay fraction is composed mainly of interstratified expanding-layer silicates containing smectite and other layers, with subsidiary mica and kaolinite and small amounts of feldspar, chlorite and crystalline (goethite) or amorphous ferric oxides (Avery and Catt, 1995).

Soils were sampled in May 1995 and 1996 using a $2 \mathrm{~cm}$ diameter auger to a depth of $23 \mathrm{~cm}$. Samples were collected from four plots of varying $\mathrm{pH}$ (Table 1). The soil samples from plots $10 \mathrm{~d}$ and 11/ 1d were subdivided into a dark brown top layer, humic rich soil, (ca. $5 \mathrm{~cm}$ ) and a bottom layer, mineral soil, (ca. $18 \mathrm{~cm}$ ). The changes in soil $\mathrm{pH}$ over time are presented in Table 2. In addition to the soils, the main vegetation on each of the plots was sampled. Two of the plots are dominated by one type of grass (Table 1). The other two plots have a mixed sward containing various grasses, legumes and forbs. For additional information on the vegetation the reader is referred to Thurston et al. (1976) and Tilman et al. (1994).

\section{EXPERIMENTAL}

\section{Sample preparation and solvent extraction}

Fresh soil and vegetation samples were initially oven dried at $60^{\circ} \mathrm{C}$. All soil samples were crushed with a pestle and mortar and subsequently sieved over a $2 \mathrm{~mm}$ and a $75 \mu \mathrm{m}$ sieve, $\mathrm{pH}$ was measured in $\mathrm{H}_{2} \mathrm{O}$ (soil: $\mathrm{H}_{2} \mathrm{O}$ 1:2.5). Dried vegetation was

Table 1. Park Grass. Treatment details, $\mathrm{pH}$ of soil $(0-23 \mathrm{~cm})$ and main vegetation

\begin{tabular}{lccc}
\hline Plot & Treatment & pH in $\mathrm{H}_{2} \mathrm{O}$ & Vegetation \\
\hline $18 / 2$ & $\mathrm{~N}_{2} \mathrm{~K} \mathrm{Mg} \mathrm{Na}$ & 7.31 & mixed \\
$10 / \mathrm{d}$ & $\mathrm{N}_{2} \mathrm{P} \mathrm{Mg} \mathrm{Na}$ & 3.84 & Anthoxanthum odoratum \\
$11 / 1 \mathrm{a}$ & $\mathrm{N}_{3} \mathrm{P} \mathrm{K} \mathrm{Mg} \mathrm{Na}$ & 6.25 & mixed \\
$11 / 1 \mathrm{~d}$ & $\mathrm{~N}_{3} \mathrm{P} \mathrm{K} \mathrm{Mg} \mathrm{Na}$ & 3.74 & Holcus lanatus \\
\hline
\end{tabular}

${ }^{\dagger} \mathrm{N}_{2}, \mathrm{~N}_{3}: 96,144 \mathrm{~kg} \mathrm{~N} \mathrm{ha}^{-1} \mathrm{yr}^{-1}$ as ammonium sulphate, P: $35 \mathrm{~kg} \mathrm{Pha}^{-1} \mathrm{y}^{-1}$ as triple superphosphate, $\mathrm{K}: 225 \mathrm{~kg} \mathrm{~K}^{-1} \mathrm{y}^{-1}$ as potassium sulphate, $\mathrm{Mg}$ : $10 \mathrm{~kg} \mathrm{Mg} \mathrm{ha}^{-1} \mathrm{y}^{-1}$ as magnesium sulphate, $\mathrm{Na}: 15 \mathrm{~kg} \mathrm{Na} \mathrm{ha}^{-1} \mathrm{y}^{-1}$ as sodium sulphate. 
Table 2. Changes in $\mathrm{pH}$ over time $(0-23 \mathrm{~cm}$ soil $)$

\begin{tabular}{lcccc}
\hline Plot & 1923 & 1959 & 1976 & 1984 \\
\hline $18 / 2$ & 5.2 & 7.5 & $7.6^{\dagger}$ & 7.1 \\
$10 / \mathrm{d}$ & 3.9 & 3.8 & 3.9 & 3.7 \\
$11 / 1 \mathrm{a}$ & 4.1 & 4.2 & $4.8^{\ddagger}$ & 6.6 \\
$11 / 1 \mathrm{~d}$ & 3.8 & 3.7 & 3.7 & 3.5 \\
\hline
\end{tabular}

${ }^{\dagger}$ Sampled in $1977 .{ }^{\star}$ Sampled in 1979.

crushed using the same method but with the addition of liquid nitrogen to facilitate the process. This was then sieved over a 5 and $2 \mathrm{~mm}$ sieve.

Soil samples (ca. $3 \mathrm{~g}$ humic soil, $10 \mathrm{~g}$ mineral soil) were Soxhlet extracted for $24 \mathrm{~h}$ using $200 \mathrm{ml}$ dichloromethane $(\mathrm{DCM}) /$ acetone $(9: 1 \mathrm{v} / \mathrm{v})$ to obtain a total lipid extract (TLE). 2-Hexadecanol $(40 \mu \mathrm{g})$ was added as an internal standard. The same internal standard $(40 \mu \mathrm{g})$ was added to vegetation samples (ca. $0.5 \mathrm{~g}$ ) which were ultrasonically extracted $(5 \times)$ with $\mathrm{DCM} /$ acetone $(9: 1 \mathrm{v} / \mathrm{v})$; total volume $50 \mathrm{ml}$. Extracts were combined and solvent removed under reduced pressure.

Redissolved residues were transferred with DCM/ isopropanol $(2: 1 \mathrm{v} / \mathrm{v})$ and filtered over defatted cotton wool. Aliquots were taken and filtered through a glass column packed with activated $\mathrm{SiO}_{2}(2 \mathrm{~g})$ to remove highly polar compounds. Samples were trimethylsilylated (see Derivatization) diluted in $n$-hexane (ca. $4 \mu \mathrm{g} \mu \mathrm{l}^{-1}$ ) and analyzed using HT-GC and HT-GC-MS. The soil and vegetation residues were analyzed using Py-GC and Py-GC-MS.

\section{Fractionation}

TLE aliquots of samples from plots 10d and 11/ 1d were fractionated to obtain mono alkanols (Lockheart et al., 1997). Briefly, solid phase extraction was used to isolate the "acid" and "neutral" fractions. The latter fraction was further separated into five fractions using silica gel flash column chromatography. The "alkanol" fraction was eluted with dichloromethane/methanol $(1: 1 \mathrm{v} / \mathrm{v})$. The $n$ alkanols were converted to trimethylsilyl ethers prior to GC and GCC-IRMS.

\section{Derivatization}

Free hydroxyl and carboxylic acid groups were derivatized to their respective trimethylsilyl (TMS) ethers and esters by adding $30 \mu \mathrm{l}$ of $N, O$-bis(trimethylsilyl)trifluoroacetamide, containing $1 \%$ trimethylchlorosilane, to sample aliquots and heating for $1 \mathrm{~h}$ at $70^{\circ} \mathrm{C}$.

High temperature-gas chromatography (HT-GC) and high temperature gas chromatography-mass spectrometry ( $H T-G C-M S)$

HT-GC was performed using a Hewlett Packard 5890 series II gas chromatograph equipped with a fused-silica capillary column (J \& W Scientific DB1, $15 \mathrm{~m} \times 0.32 \mathrm{~mm}$, film thickness $0.1 \mu \mathrm{m})$. Derivatized total lipid extracts $(1.0 \mu \mathrm{l})$ in hexane were injected on-column. The temperature was programmed from $50^{\circ} \mathrm{C}(2 \mathrm{~min})$ to $350^{\circ} \mathrm{C}(10 \mathrm{~min})$ at a rate of $10^{\circ} \mathrm{C}$ $\mathrm{min}^{-1}$. The detector temperature was $350^{\circ} \mathrm{C}$. Hydrogen was used as carrier gas. The HT-GC-MS analyses were performed using a Carlo Erba 5160 mega series gas chromatograph connected to a Finnigan 4500 mass spectrometer operating at $70 \mathrm{eV}$, scanning the range $m / z 50-850$ in a cycle time of $1.5 \mathrm{~s}$. The interface temperature was $350^{\circ} \mathrm{C}$. The capillary column and temperature programme were as described for the HT-GC analyses. Compound identification was based on mass spectral data and retention time comparisons with reference samples.

\section{Gas chromatography (GC)}

The derivatized alkanol fractions were analyzed using a Hewlett Packard 5890 series II gas chromatograph equipped with a fused-silica capillary column (Chrompack CPSil-5CB, $50 \mathrm{~m} \times 0.32 \mathrm{~mm}$, film thickness $0.12 \mu \mathrm{m})$. Derivatized total lipid extracts $(1.0 \mu \mathrm{l})$ in hexane were injected on-column. The temperature was programmed from $40^{\circ} \mathrm{C}$ (1 min) to $200^{\circ} \mathrm{C}$ at a rate of $10^{\circ} \mathrm{C} \mathrm{min}^{-1}$ and finally to $300^{\circ} \mathrm{C}(20 \mathrm{~min})$ at $3^{\circ} \mathrm{C} \mathrm{min}^{-1}$. The detector temperature was $320^{\circ} \mathrm{C}$. Hydrogen was used as carrier gas.

Gas chromatography combustion-isotope ratio mass spectrometry (GCC-IRMS)

Stable carbon isotope ratios $\left(\delta^{13} \mathrm{C}\right)$ were measured on a Varian 3400 GC (SPI-type injector tracking oven temperature) coupled to a Finnigan MAT Delta S instrument. Separation was achieved using a fused silica capillary column (SGE BP-1, $50 \mathrm{~m} \times 0.32 \mathrm{~mm}, 0.25 \mu \mathrm{m}$ film thickness). The combustion oven was held at $850^{\circ} \mathrm{C} . \delta^{13} \mathrm{C}$ values were calibrated relative to the PeeDee Belemnite standard. Calculations to correct for the three exogenous carbon atoms present in the trimethylsilyl group of the derivatized alkanols were performed after $\delta^{13} \mathrm{C}_{\mathrm{tms}}$ was determined from a cholesterol standard of known isotopic composition (cf. Jones et al., 1991).

Flash pyrolysis-gas chromatography $(P y-G C)$ and flash pyrolysis-gas chromatography-mass spectrometry (Py-GC-MS)

Py-GC analyses were performed using a Horizon Instruments Curie-point pyrolyser attached to a Carlo Erba 4160 GC. The samples were pressed onto a ferromagnetic wire with a Curie temperature of $610^{\circ} \mathrm{C}$. The interface temperature of the pyrolysis unit was set at $250^{\circ} \mathrm{C}$ and the pyrolysis time was $10 \mathrm{~s}$. The GC oven was programmed from $30^{\circ} \mathrm{C}$ $(5 \mathrm{~min})$ to $320^{\circ} \mathrm{C}(10 \mathrm{~min})$ at a rate of $4{ }^{\circ} \mathrm{C} \mathrm{min}^{-1}$. Separation was achieved using a fused-silica capillary column (Chrompack CPSil-5CB, 


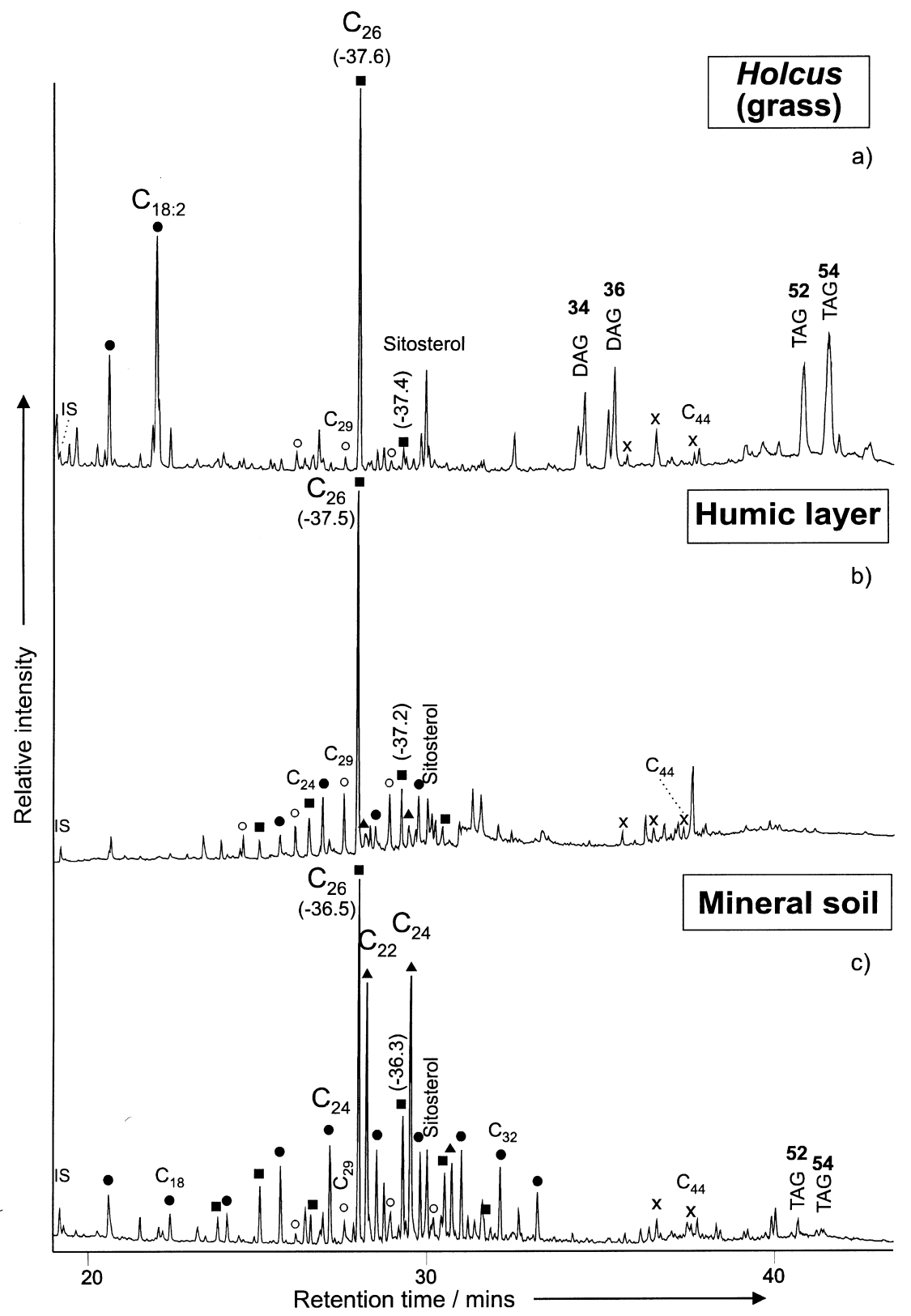

Fig. 1. Partial gas chromatograms of the total lipid extracts from plot 11/1d (pH 3.74); (a) grass Holcus, (b) humic top layer and (c) mineral soil. Key: IS ${ }_{x}=$ Internal Standards; 0 = fatty acids; $\mathrm{O}=n$-alkanes; $\boldsymbol{\boldsymbol { U }}=n$-alkanols; $\boldsymbol{\Delta}=\omega$-hydroxy fatty acids; $\mathrm{x}=$ wax esters; $\mathrm{DAG}=$ diacylglycerols; $\mathrm{TAG}=$ triacylglycerols; $\mathrm{C}_{x x}$ refers to total carbon numbers; numbers in bold indicate total acyl carbons. $\delta^{13} \mathrm{C}$ values are indicated in parenthesis. These were measured on purified alkanol fractions and not on the TLEs.

$25 \mathrm{~m} \times 0.32 \mathrm{~mm}$, film thickness $0.4 \mu \mathrm{m})$. Helium was used as the carrier gas. Py-GC-MS analyses were performed using a Carlo Erba 4130GC equipped with a CDS 1000 pyroprobe pyrolysis device coupled to a Finnigan 4500 mass spectrometer. Compounds were separated using a $50 \mathrm{~m}$ Chrompack CPSil-5 CB column $(0.32 \mathrm{~mm}$ i.d., film thickness $0.4 \mu \mathrm{m})$. Each sample was loaded into a quartz tube and pyrolyzed at $610^{\circ} \mathrm{C}$ in a flow of helium for $10 \mathrm{~s}$. Compound identification was based on mass spectral data and retention time comparisons with reference samples.

\section{RESULTS AND DISCUSSION}

Both DCM/acetone soluble and insoluble soil organic matter fractions were studied with a view to providing new information about the influence of 


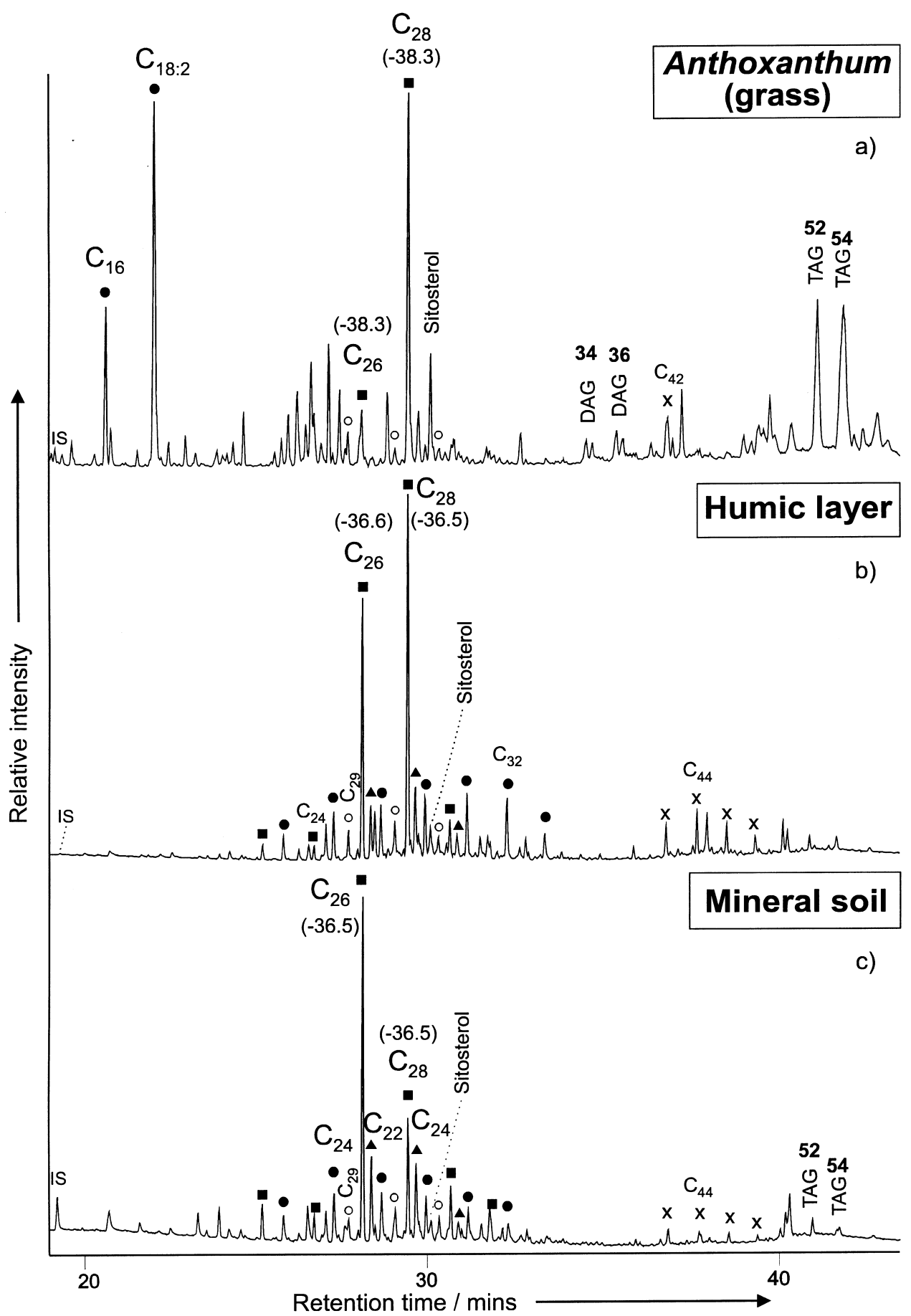

Fig. 2. Partial gas chromatograms of the total lipid extracts from plot $10 \mathrm{~d}(\mathrm{pH} 3.84)$; (a) grass Anthoxanthum, (b) humic top layer and (c) mineral soil. Peak identification as for Fig. $1 . \delta^{13} \mathrm{C}$ values are indicated in parenthesis. These were measured on purified alkanol fractions and not on the TLEs.

soil $\mathrm{pH}$ on the degradation and preservation of plant derived biomolecules. The gas chromatograms of the total lipid extracts and the pyrolysates of the vegetation and soil samples showed significant differences in the distributions of the low and high molecular weight compounds present.

\section{n-Alkanols}

The TLEs for the majority of vegetation samples exhibited a $\mathrm{C}_{26}$ component as the most prevalent $n$ alkanol [Fig. 1(a), Fig. 3(a), Fig. 4(a) and Fig. 5(a)] and in most plots it was the predominant com- 


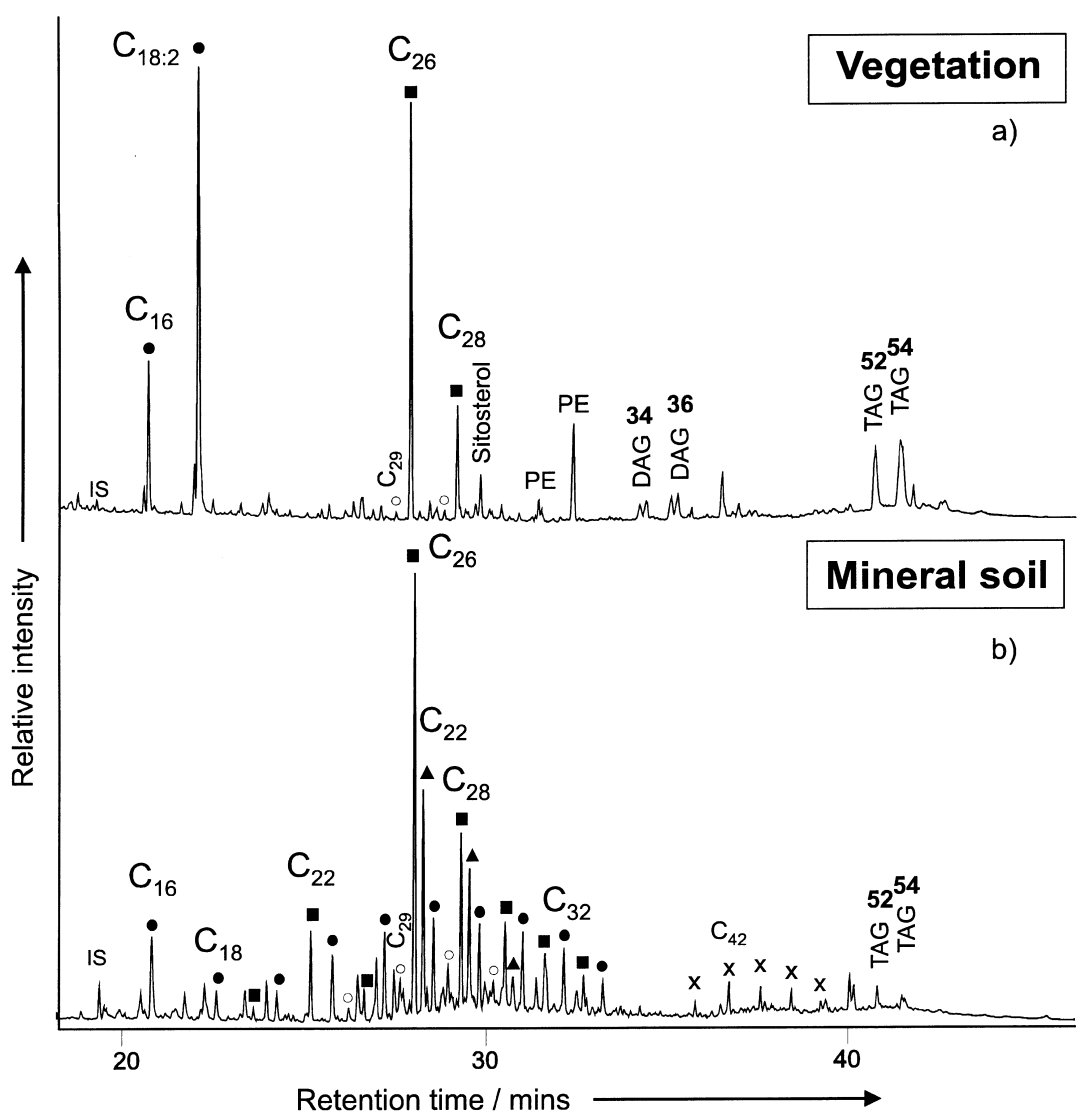

Fig. 3. Partial gas chromatograms of the total lipid extracts from plot 11/1a (pH 6.25); (a) vegetation (mainly grass), (b) mineral soil. PE means phytyl esters; Peak identification as for Fig. 1.

pound present; the exception being plot 10d, in which the $\mathrm{C}_{28}$ alkanol dominated [Fig. 2(a)]. The soil extracts [Fig. 1(b) and (c), Fig. 2(b) and (c), Fig. 3(b), Fig. 4(b) and Fig. 5(a)] were also dominated by $n$-alkanols $\left(\mathrm{C}_{20}-\mathrm{C}_{34}\right)$ and, with the exception of plot 10d top soil [Fig. 2(b)], $\mathrm{C}_{26}$ was again the dominant component.

The very strong even over odd prevalence of $n$ alkanols, with a carbon range $\mathrm{C}_{22}-\mathrm{C}_{32}$, in the soil extracts is characteristic of higher plant wax (Walton, 1990). However, there was a marked difference in the distribution of long chain even $n$ alkanols between the vegetation and soil samples; in particular, a decrease in the relative abundance of the $\mathrm{C}_{26} n$-alkanol [Fig. 5(a)]. In the alkaline soil [Fig. 4(b)] the $n$-alkanols were one of the most dominant compound classes a phenomenon also observed in other alkaline soils from Rothamsted (van Bergen et al., 1997a,b; Bull et al., 1998).

The $\mathrm{C}_{26} n$-alkanol is a well-known abundant constituent in many grasses (Tulloch, 1976), confirmed by our analyses of vegetation samples, except that from plot 10d. The prevalence of this dominant $C_{26}$ $n$-alkanol through the soil profile appears to imply that the grass signal has remained in the solvent soluble fraction of the soil. However, one exception to this trend was the TLE of the vegetation from plot $10 \mathrm{~d}$ which was dominated by the $\mathrm{C}_{28} n$-alkanol [Fig. 2(a)]. This plot is directly adjacent to plot $11 /$ $1 \mathrm{~d}$ and, like plot $11 / 1 \mathrm{~d}$, has a low soil $\mathrm{pH}$ (plot 11 1d, $\mathrm{pH} 3.74$ and plot 10d, $\mathrm{pH} 3.84$ ). The major treatment difference is that plot $11 / 1$ receives potassium fertilizer, while plot 10 does not. Each plot is now covered by a single but different grass species, Holcus lanatus on 11/1d and Anthoxanthum odoratum on 10d (Table 1). Interestingly, the TLEs of these two species were dominated by different $n$ alkanols, $\mathrm{C}_{26}$ in $H$. lanatus and $\mathrm{C}_{28}$ in $A$. odoratum [Fig. 1(a) vs. Figure 2(a)]. In common with the vegetation, the $0-5 \mathrm{~cm}$ and $5-23 \mathrm{~cm}$ soil layers of subplot $11 / 1 \mathrm{~d}$ contained a $\mathrm{C}_{26} n$-alkanol as the most prominent component (Fig. 1), suggesting a direct derivation from vegetation to soil. In contrast, the distribution of the $n$-alkanols changed dramatically in the soil of plot $10 \mathrm{~d}$ (Fig. 2). The $\mathrm{C}_{28} n$-alkanol decreased sharply in relative abundance from the 


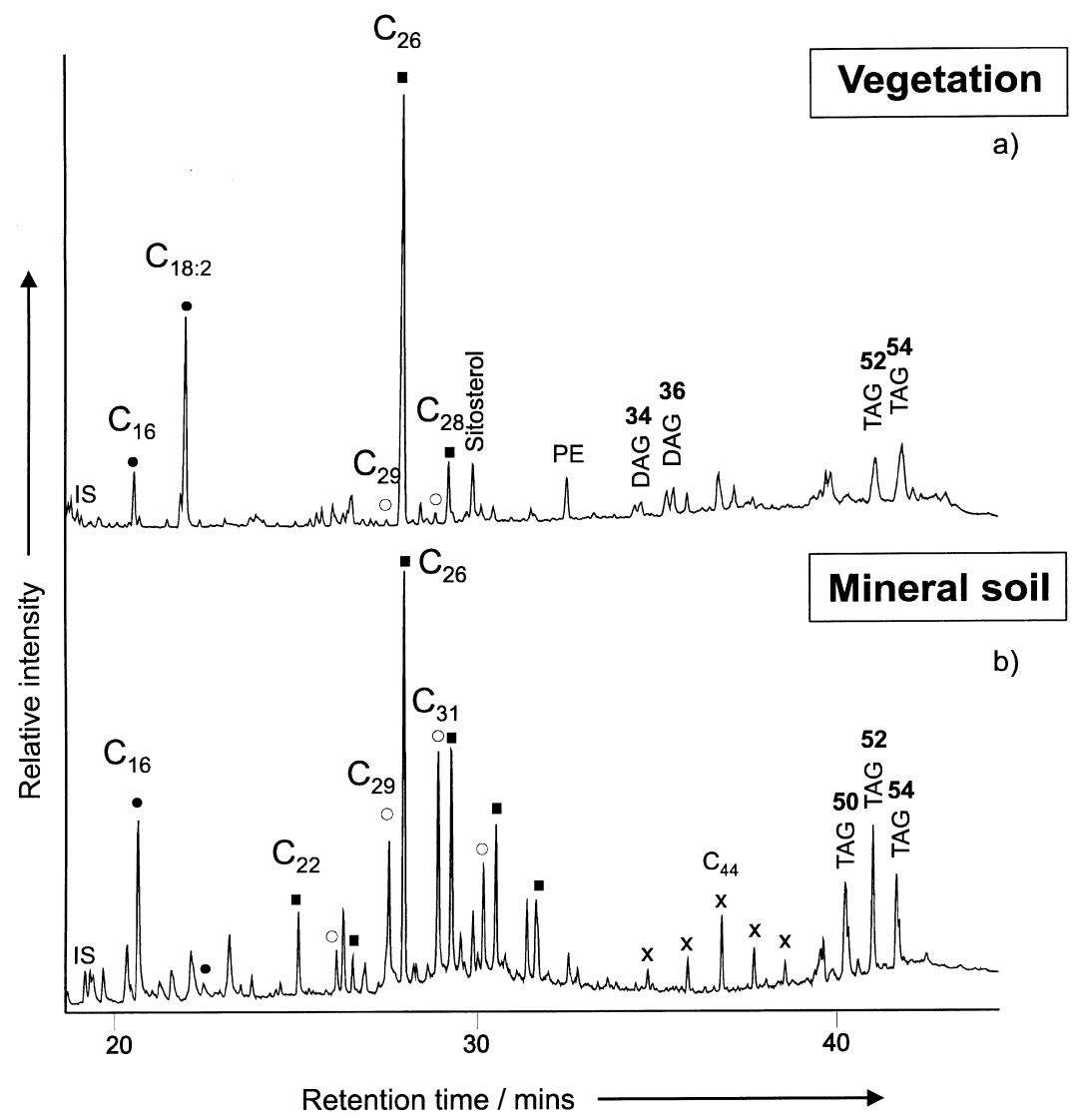

Fig. 4. Partial gas chromatograms of the total lipid extracts from plot 18/2 (pH 7.31); (a) vegetation (mainly grass), (b) mineral soil. PE means phytyl esters; Peak identification as for Fig. 1.

humic to mineral layer. This observation clearly shows that the signal of the low molecular weight fraction in the deeper soils is not directly related to the current vegetation but is more probably derived either from previous vegetation, when Anthoxanthum was not so dominant, or from soil dwelling organisms (e.g. mesofauna, fungi, etc.).

The idea of a lower contribution of vegetation derived organic matter to the SOM on plot $10 \mathrm{~d}$ is further substantiated by the $\delta^{13} \mathrm{C}$ data of the $n$-alkanols from $10 \mathrm{~d}$ and $11 / 1 \mathrm{~d}$. The $\delta^{13} \mathrm{C}$ values of the $\mathrm{C}_{26}$ and $\mathrm{C}_{28} n$-alkanols (Figs 1 and 2) of the vegetation were consistent with values reported in the literature for long-chain hydrocarbons (Collister et al., 1994). The values of the alkanols in both mineral soils were very similar but were slightly less depleted in ${ }^{13} \mathrm{C}$ (ca. $-36.5 \%$ ) compared with the vegetation (ca. -37.5 and $-38.3 \%$ ). While the isotope values of the $n$-alkanols in the humic layer of plot $10 \mathrm{~d}$ resembled those of the mineral soil [ca. $-36.5 \%$; Fig. 2(b) and (c)], the $n$-alkanols of plot $11 / 1 \mathrm{~d}$ were similar to those of the standing vegetation [ca. $-37.4 \%$; Fig. 1(a) and (b)]. This is concordant with a slower incorporation of the
Anthoxanthum OM into the soil organic matter and thus the presence of more "old" carbon in the humic layer of plot 10d compared with plot 11/1d.

Alkanes

n-Alkanes ranging from $\mathrm{C}_{27}$ to $\mathrm{C}_{33}$ were also present in the vegetation extracts [Fig. 1(a), Fig. 2(a), Fig. 4(a) and Fig. 5(b)]. In the extracts of the soils $n$-alkanes were relatively more abundant and ranged from $\mathrm{C}_{25}$ to $\mathrm{C}_{33}$ with $\mathrm{C}_{29}$ or $\mathrm{C}_{31}$ dominating [Fig. 1(b) and (c), Fig. 2(b) and (c), Fig. 3(b), Fig. 4(b) and Fig. 5(b)]. In all soils the $\mathrm{C}_{33}$ homologue increased in abundance compared with the vegetation [Fig. 5(b)]. The soil extract from plot 18/ 2 showed the highest relative abundances of $n$ alkanes [Fig. 4(b)].

The $n$-alkanes present in the TLEs of the vegetation showed the predominance of odd chain members characteristic of higher plant waxes (Walton, 1990). This predominance prevailed throughout the soil extracts implying a plant input. There was a higher relative abundance of the longer chain $n$-alkanes in the soil samples with an alkaline pH [Fig. 4(b)], a phenomenon also observed in soil 


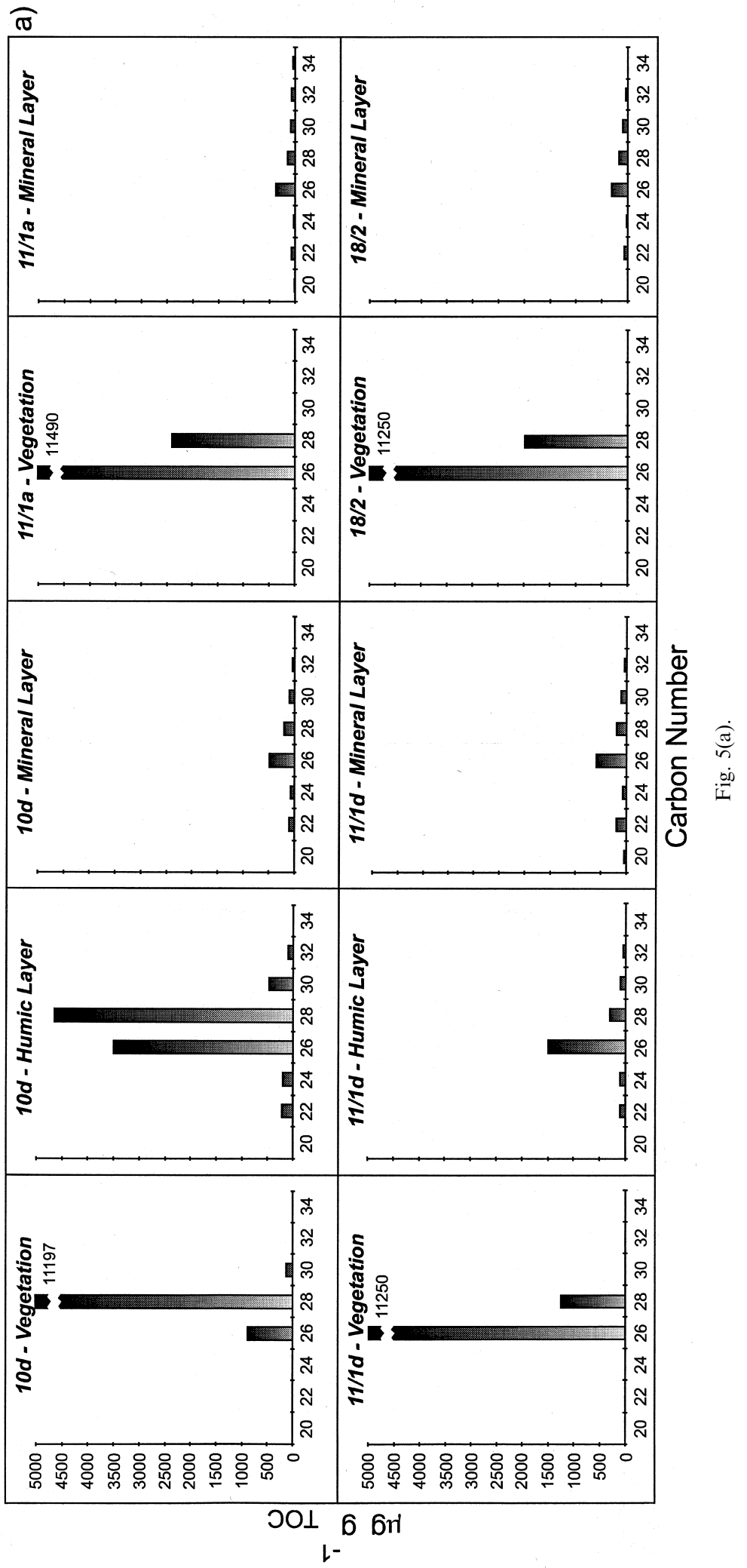




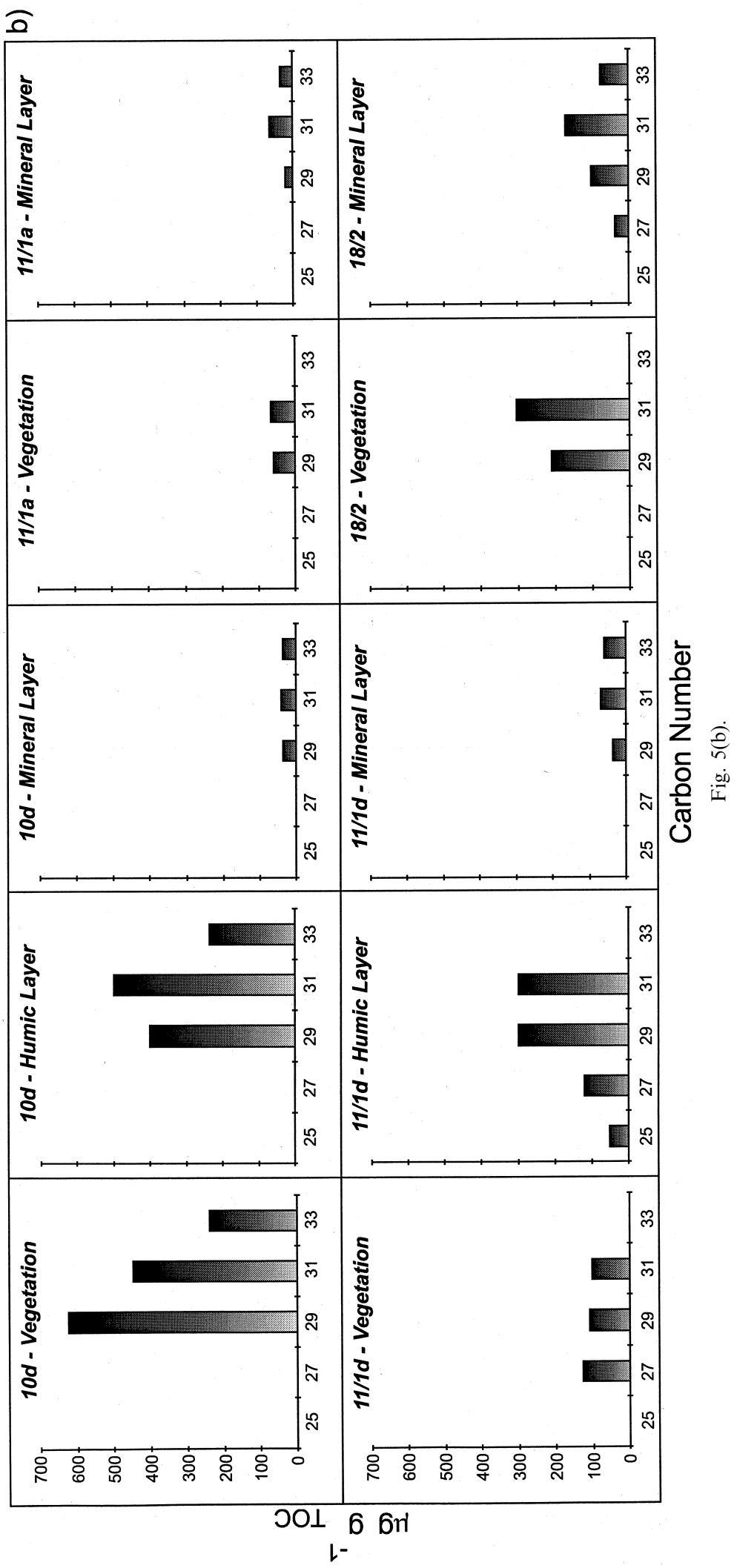




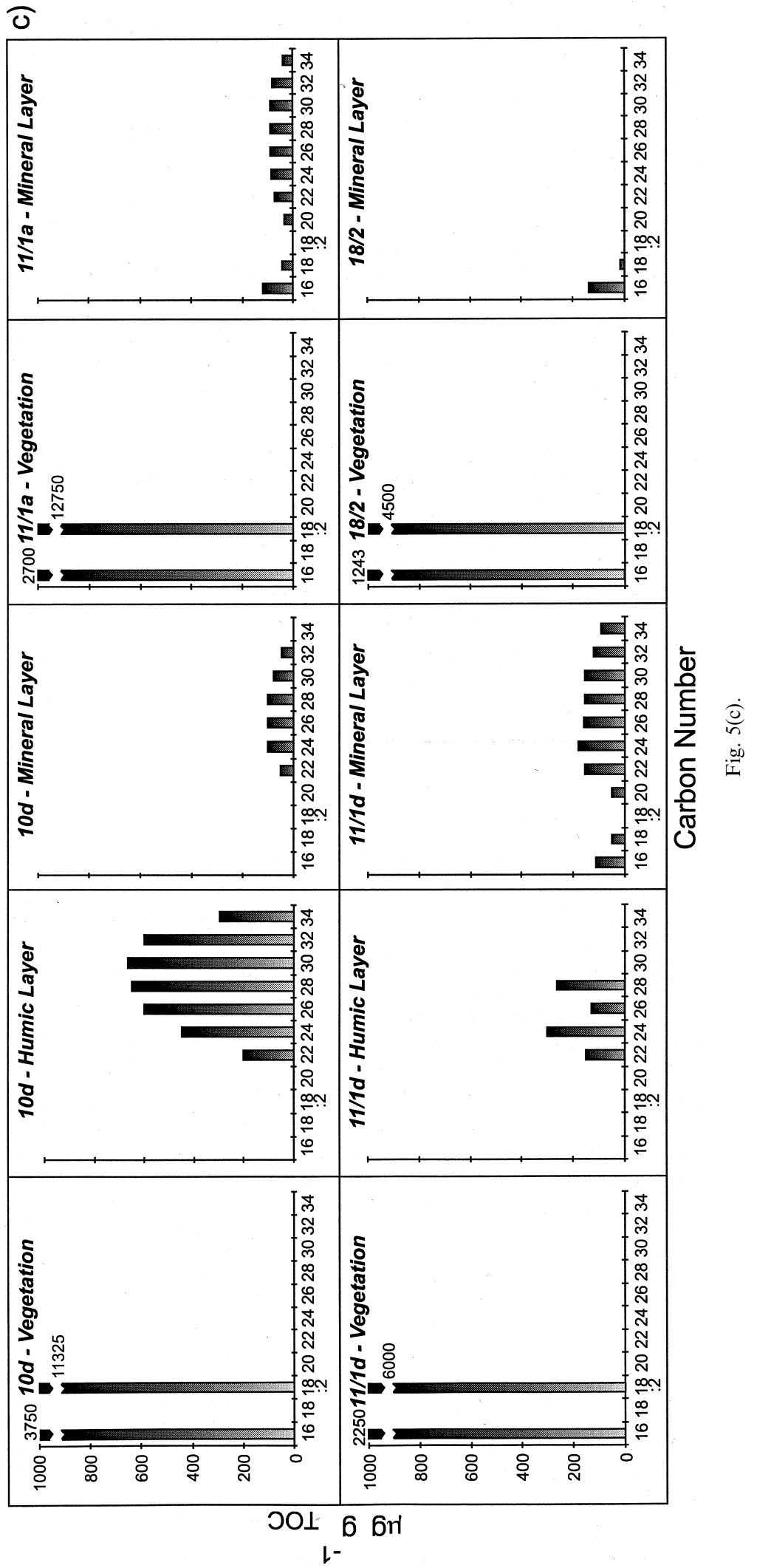




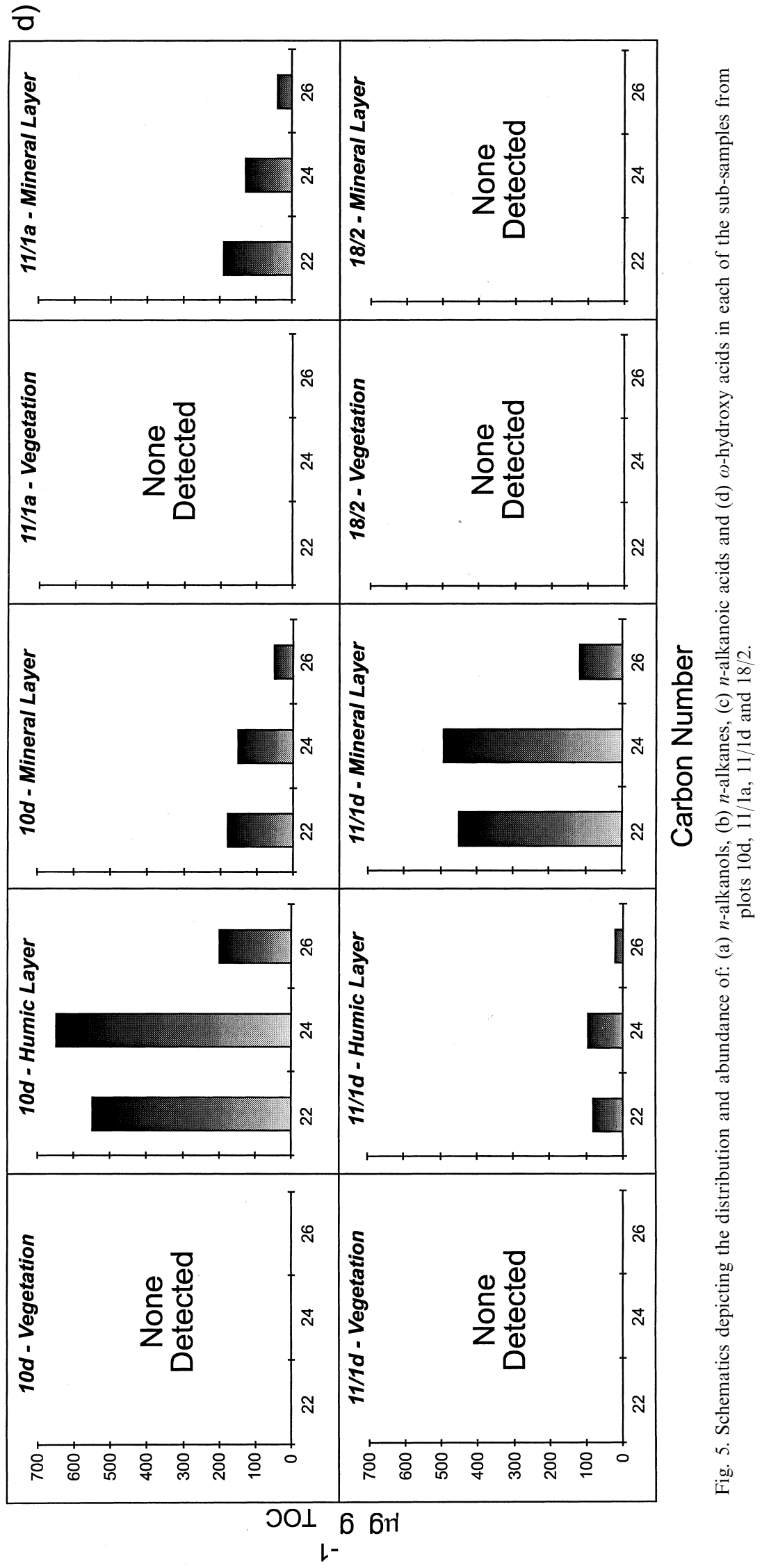


extracts from other sites at Rothamsted with alkaline soils (Broadbalk Wilderness; van Bergen et al., 1997a). Since the relative abundance of the alkanes in most of the vegetation samples was similar, it appears to indicate that a high $\mathrm{pH}$ may help to preserve vegetation derived alkanes relative to other compound classes. However, a contribution from soil organisms such as fungi cannot be excluded (Weete, 1976).

\section{Alkanoic and alkenoic acids}

There were distinct differences in the distributions of $n$-alkanoic acids between the vegetation and soil samples. The extracts of the vegetation contained, primarily, shorter chain alkanoic and alkenoic acids, many of which were polyunsaturated $\left[\mathrm{C}_{16}\right.$, $\mathrm{C}_{18: 3}$ and $\mathrm{C}_{18: 2}$; Fig. 1(a), Fig. 2(a), Fig. 3(a), Fig. 4(a) and Fig. 5(c)]. In the soil extracts, $n$-alkanoic acids, ranging from $\mathrm{C}_{16}$ to $\mathrm{C}_{34}$ and maximising at $\mathrm{C}_{24}, \mathrm{C}_{26}$ and $\mathrm{C}_{28}$, were relatively abundant, particularly in acidic soils (Figs 1-3 and Fig. 5(c)]. In comparison with the vegetation, polyunsaturated $\mathrm{C}_{18}$ alkanoic acids and the saturated $\mathrm{C}_{16} n$-alkanoic acid were present in dramatically lower relative abundance in the soil extracts.

$n$-Alkanoic acids in soils can derive directly from vegetation (Amblès et al., 1994). Alternatively, they originate from oxidation of a variety of other compounds such as $n$-alkanes and $n$-alkanols (Moucawi et al., 1981; Amblès et al., 1994). Apart from some direct input, we believe that the most likely source for the acids is oxidation of plant derived lipids from vegetation. Whether the low soil $\mathrm{pH}$ is conducive to the formation of these organic acids, or that the presence of the organic acids causes the low soil $\mathrm{pH}$ is as yet unclear. An interesting observation in this respect was the relative abundance of $n$-alkanoic acids in the soil extract of plot 11/1a [Fig. 3(b)]. At present the soil $\mathrm{pH}$ of this plot is 6.25 , but until the late 1970s this soil had a pH of 4.8 (Table 2). Thus, the presence of the organic acids apparently does not substantially affect the current soil $\mathrm{pH}$. It does, however, imply that the low molecular weight signal in the soil is strongly affected by previous inputs/treatments with the abundance of alkanoic acids being a result of previous (acidic) soil conditions.

Branched chain, $\mathrm{C}_{15}$ and $\mathrm{C}_{17}$ iso- and anteisoalkanonic acids were only detected in the extracts of the soils and not in those of the vegetation. These provide molecular evidence for microbial activity (Amblès et al., 1994). Branched-chain alkanoic acids are common constituents in soil extracts (Amblès et al., 1994; Bull et al., 1998).

Other distinct classes of alkanoic acids not detected in the vegetation, but present in the soil extracts, were the $\alpha, \omega$-diacids $\left(\mathrm{C}_{22}\right.$ and $\mathrm{C}_{24}$; not annotated) and $\omega$-hydroxy-acids $\left(\mathrm{C}_{20}, \mathrm{C}_{22}, \mathrm{C}_{24}\right.$, $\mathrm{C}_{26}$ ). In particular the $\mathrm{C}_{22}$ and $\mathrm{C}_{24} \omega$-hydroxy-acids became relatively important in all soil extracts [Figs 1-3 and Fig. 5(d)] apart from alkaline soil 18/ 2 . In the plots with a distinct humic layer the relative abundances of the hydroxy acids and diacids were relatively greater in the extracts of the deeper $(5-23 \mathrm{~cm})$ mineral soil [Fig. 1(c), Fig. 2(c) and Fig. 5(d)]. The reason for the presence of the hydroxy acids in the soil extract of plot $11 / 1 \mathrm{a}$ is believed to be related to the fact that this plot had, until recently, a low soil $\mathrm{pH}$ (see earlier).

The origin of the $\omega$-hydroxy acids is as yet not completely clear. It is unlikely that these compounds are derived directly from oxidation of the alkanols in the vegetation as this would give primarily $\mathrm{C}_{26}$ or $\mathrm{C}_{28} \omega$-hydroxy acids. The most abundant "free acids" in the grass are the $\mathrm{C}_{26}$ and $\mathrm{C}_{28}$ $n$-alkanoic acids (Walton, 1990), so these are also unlikely substrates. Few plant biomolecules contain predominantly specific $\mathrm{C}_{22}$ and $\mathrm{C}_{24} \omega$-hydroxy acid building blocks. One obvious precursor is suberin, since this biopolymer has been reported to contain substantial amounts of either the $\mathrm{C}_{22}$ and/or the $\mathrm{C}_{24}$ homologues (Walton, 1990; Matzke and Riederer, 1991; Riederer et al., 1993). Base treatment of $H$. lanatus root material released $\mathrm{C}_{22}$ and $\mathrm{C}_{24} \omega$-hydroxy acid (Bull, Nott and Evershed, unpublished results). Thus, these hydroxy acids most likely originate from (microbially) hydrolysed biopolyesters present in root material. Regarding the diacids (not shown), their relative abundance increased with that of the $\omega$-hydroxy acids. Furthermore, both the hydroxy acids and the diacids were dominated by the $\mathrm{C}_{22}$ and $\mathrm{C}_{24}$ homologues. Like the $\omega$-hydroxy acids, the $\mathrm{C}_{22}$ and $\mathrm{C}_{24}$ diacids are also known to be moieties present in suberin. We, therefore, propose that these compounds are most likely derived from hydrolysed suberin. However, direct oxidation of the root derived $\omega$-hydroxy acids may also have contributed.

\section{Alkyl esters}

The vegetation extracts showed various classes of alkyl esters including wax esters $\left(\mathrm{C}_{40}\right.$ to $\left.\mathrm{C}_{48}\right)$, diacylglycerols (DAGs) and two triacylglycerol envelopes (TAG; $\mathrm{C}_{52}$ and $\mathrm{C}_{54}$ containing $\mathrm{C}_{16: 0}, \mathrm{C}_{18: 2}$, $\mathrm{C}_{18: 3}$, and $\mathrm{C}_{18: 2}, \mathrm{C}_{18: 3}, \mathrm{C}_{18: 2}$ fatty acyl moieties, respectively). In most soil extracts, both DAGs and TAGs have reduced substantially in relative abundance most probably due to hydrolysis and assimilation by soil organisms. Only in the extract of the alkaline soil [Fig. 4(b)] were the TAGs were still prominent. Furthermore, this extract clearly revealed the presence of a $\mathrm{C}_{50}$ TAG providing evidence of transesterification as previously suggested by Amblès et al. (1994).

In all vegetation samples where the $\mathrm{C}_{26} n$-alkanol dominated, the wax esters were based on this alkanol. In contrast the wax esters in the vegetation extract from $10 \mathrm{~d}$ were based on the $\mathrm{C}_{28}$ alkanol. A 
similar phenomenon was observed in the soil extracts where all wax esters were based on $\mathrm{C}_{26} n$ alkanol moieties, apart from in the TLE of soil from the top $5 \mathrm{~cm}$ of $10 \mathrm{~d}$ [Fig. 2(b)]. The wax esters in this sample were based both on $\mathrm{C}_{26}$ and $\mathrm{C}_{28}$ nalkanol moieties reflecting the free $n$-alkanol distribution [Fig. 2(b)]. Thus like the free $n$-alkanols, the wax esters provide evidence for some Anthoxanthum

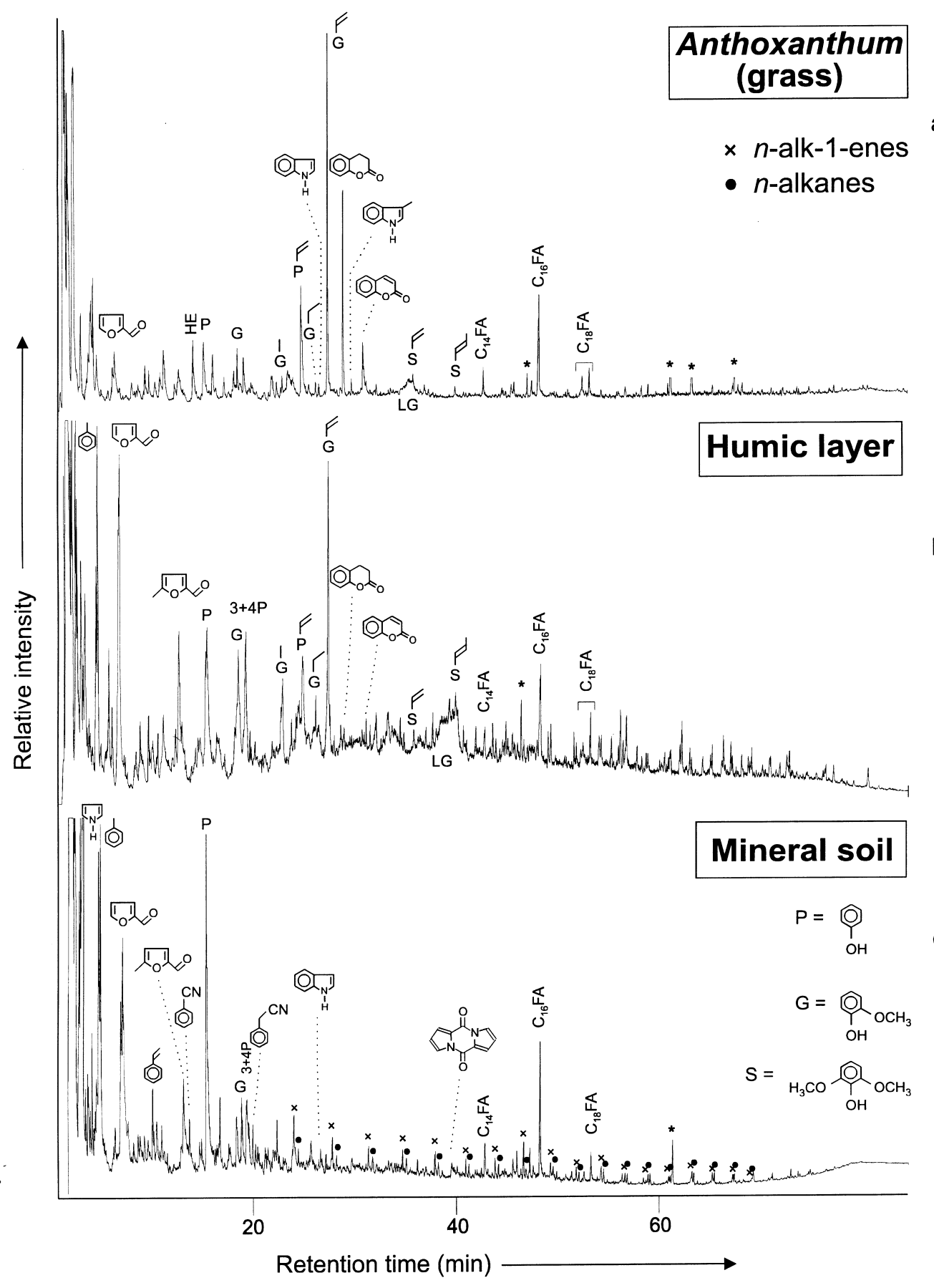

Fig. 6. Gas chromatograms of the pyrolysates (Curie-temperature $610^{\circ} \mathrm{C}$ ) of the residues of (a) Anthoxanthum, (b) humic top layer and (c) mineral soil from plot $10 \mathrm{~d}(\mathrm{pH} 3.84)$. Key: $\mathrm{P}=$ means phenol, $3+4 \mathrm{P}=$ co-eluting 3- and 4-methylphenol, $\mathrm{C}_{16} \mathrm{FA}=$ hexadecanoic acid, $\mathrm{HE}=$ Hemicellulose marker, $L G=$ Levoglucosan; $C_{x x}$ refers to total carbon numbers. $*=$ are contaminants. Side chains (attached at positions 4) of phenol-(P), 2-methoxyphenol-(guaiacyl; G) and 2,6-dimethoxyphenol-(syringyl-; S) components are indicated. 
input. Pedological hydrolysis of the wax esters based on the $\mathrm{C}_{26} n$-alkanols may be the source for the increase in free 1-hexacosanol [Fig. 2(b)]. The $\mathrm{C}_{26} n$-alkanol based wax esters in the top layer of plot $10 \mathrm{~d}$ are most probably derived from wax esters of other grasses, such as $H$. lanatus, which are known to have grown on this plot until the early 1970s (Thurston et al., 1976).

\section{2-Alkanones}

2-Alkanones $\left(\mathrm{C}_{29}-\mathrm{C}_{35}\right.$; not annotated $)$ were present in relatively low amounts in the soil extracts, but were not detected in the vegetation. Like the branched short-chain fatty acids, these provide evidence for microbial activity. 2-Alkanones are not primary plant products and their presence in soils suggests in situ microbial oxidation of other lipid components (Amblès et al., 1993). The most likely substrates for these compounds in the soils were $n$ alkanes as the carbon number distribution of the alkanones was also dominated by odd carbon number long-chain homologues. Fatty acids, which can also be a source for 2-alkanones, are considered to be only minor contributors because of the differences in their distribution patterns.

\section{Macromolecular SOM}

The Py-GC profiles of the solvent insoluble organic matter in the vegetation samples were dominated by phenols, 2-methoxyphenols, 2,6dimethoxyphenols and polysaccharide pyrolysis products [cf. Figure 6(a)]. In particular, 4-ethenylphenol and 4-ethenyl-2-methoxyphenol were abundant pyrolysis products. These results clearly indicate the presence of angiosperm lignin-cellulose (SaizJimenez and de Leeuw, 1986). More specifically they indicate the presence of monocotyledon lignincellulose, based on the identification of abundant 4ethenylphenol and 4-ethenyl-2-methoxyphenol (van Bergen et al., 1997a,b). The precursors for these compounds are $p$-coumaric acid and ferulic acid, respectively.

The pyrolysis of the grass from plot 10d (A. odoratum) also yielded two specific products tentatively identified as coumarin and dihydrocoumarin [Fig. 6(a)]. These products are most probably derived from coumarin glycosides which have been reported previously from A. odoratum (Paris, 1963; Yamamoto, 1995). It should be noted that these compounds were not detected in any of the other vegetation samples.

The pyrolysates of humic rich top soil layers [Fig. 6(b)] resemble that of the vegetation, in particular with respect to the characteristic methoxyphenols. A vegetation-derived signal is further substantiated by the detection of small amounts of the same specific coumarin-type products in the pyrolysate of the humic rich layer of plot $10 \mathrm{~d}$. This indicates that the high molecular weight constituents of the vegetation contribute substantially to the SOM of humic rich layers. This phenomenon regarding a distinct lignin signal in the humic rich layer has also been observed in soil samples from Geescroft Wilderness, another site at Rothamsted that has a low soil pH (van Bergen et al., 1998).

In sharp contrast the pyrolysates of the mineral soils, showed no obvious lignin signal but were all dominated by pyrrole, toluene and phenol [Fig. 6(c) and Fig. 7). Apart from pyrrole, numerous other nitrogen-containing products were released, including pyridine, benzonitrile, acetobenzonitrile, indole, methylindole and diketodipyrrole. These products

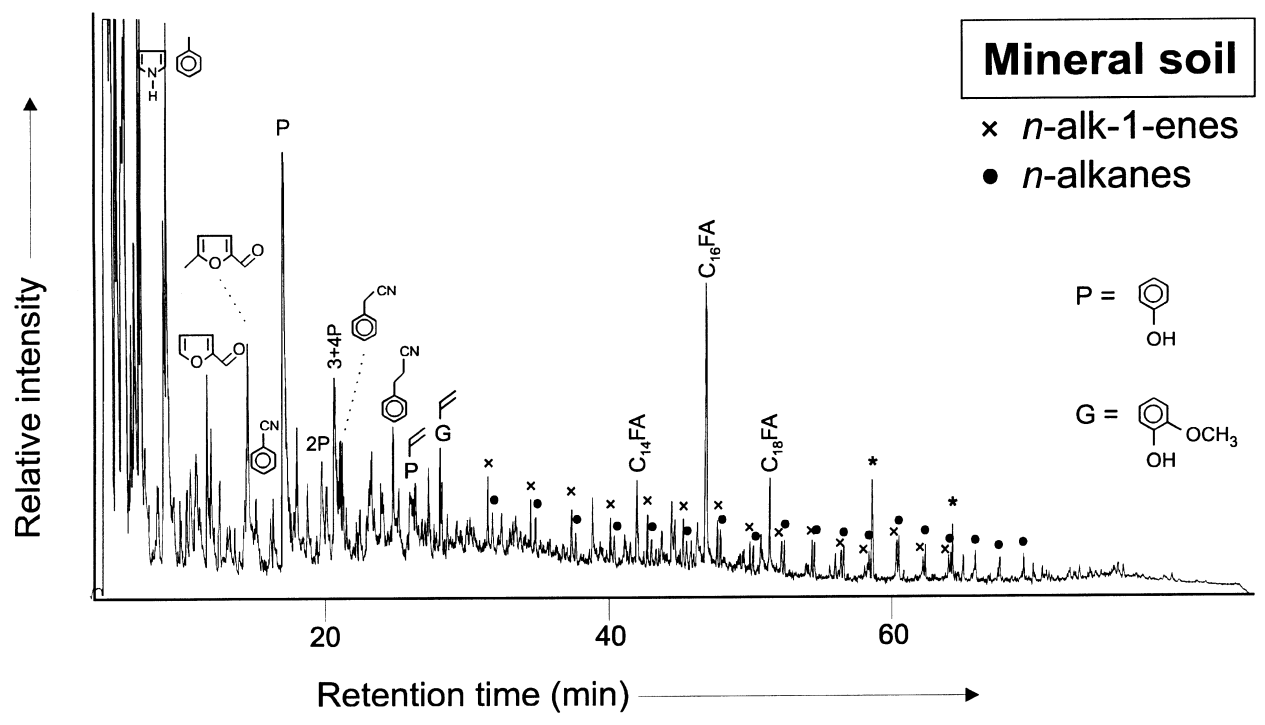

Fig. 7. Gas chromatograms of the pyrolysates (Curie-temperature $610^{\circ} \mathrm{C}$ ) of the residues of mineral soil from plot 18/2 (pH 7.31). Peak identification as for Fig. 6. 
are most probably derived from amino sugar or amino acid moieties (Bracewell and Robertson, 1984; van Bergen et al., 1997a, 1998). Whether these moieties are still present as intact polypeptides or as modified entities is as yet unknown. However, the presence of rather unusual isomers of some nitrogen-containing products could imply that these are derived from chemically modified biomolecules formed in the soil (cf. van Bergen et al., 1998).

The mineral soil pyrolysates also revealed homologous series of $n$-alkanes and $n$-alk-1-enes [Fig. 6(c), Fig. 7] providing evidence for the presence of highly aliphatic moieties. The origin of such moieties are still a matter of debate (Tegelaar et al., 1989; Augris et al., 1998). Possible sources are higher plant macromolecules such as cutan, suberan and suberin (Tegelaar et al., 1989; Augris et $a l .$, 1998) or soil derived molecules, either through selective preservation of an aliphatic biomolecule from a soil organism or through chemical recombination (Lichtfouse et al., 1995). We consider aliphatic moieties from root material and/or soil microorganisms the most likely precursors.

The pyrolysate of the soil 18/2 with a higher $\mathrm{pH}$ and no distinct layers, resembled that of the deeper layer in the samples with a low $\mathrm{pH}$, in that it was dominated by simple phenols and nitrogen-containing compounds. The pyrolysate did, however, show some evidence of a lignin contribution. Comparison of pyrolysates of soil obtained from $0-5 \mathrm{~cm}$ and 5$23 \mathrm{~cm}$ (as a comparison with the acidic soils) at plot $18 / 2$ revealed no differences between these two and no enhanched lignin signal in the top $0-5 \mathrm{~cm}$ layer. Observations of a low lignin contribution have been made on other soils with high $\mathrm{pH}$ from Rothamsted (van Bergen et al., 1997a) quite clearly demonstrating the reduction in organic matter breakdown on the more acid soils (cf. Motavalli et al., 1995). These results provide further molecular evidence for the reduced preservation of lignin on alkaline soils a phenomenon also seen at Broadbalk Wilderness (van Bergen et al., 1997a) and subsequently also observed on grass upland soil horizons (Huang et al., 1998).

\section{CONCLUSIONS}

Both total lipid extracts (TLEs) and the solvent insoluble organic matter from soils with different $\mathrm{pH}$ obtained from plots at Park Grass, Rothamsted, were studied using high temperature GC and Py-GC. The plots selected for study had $\mathrm{pH}$ values ranging from 3.7 to 7.3 . The soil and the vegetation growing on these plots were analyzed to determine whether $\mathrm{pH}$ had an effect on the preservation/ degradation of plant derived molecules. The principle findings of the investigation can be summarised as follows:
1. The TLEs of the soil samples with low $\mathrm{pH}$ revealed higher relative abundances of organic acids. These are believed to indicate oxidation of lipids most probably derived from vegetation and a contribution from hydrolysed biopolyesters from roots.

2. The signature of the present vegetation in the low molecular weight fraction is only retained in the humic rich top layer. The signal in the mineral layer is believed to derive from previous vegetation or from soil biomass (based on the detection of a $\mathrm{C}_{26} n$-alkanol in the plot $10 \mathrm{~d}$ mineral soil and the shift in isotope values).

3. There is apparently less oxidation in the samples with high $\mathrm{pH}$ as judged by the lower relative amounts of organic acids. The abundance of organic acids in plot $11 / 1$ a probably results from the fact that this plot has been acidic in the recent past.

4. The isotopic data of the $n$-alkanols of the humic rich top layer are indicative of differing rates of incorporation for the lipids possibly related to the vegetation type.

5. In the soil samples with low $\mathrm{pH}$, lignin contributes to the high molecular weight fraction in the humic top soil layer. In contrast the mineral soil shows little evidence of lignin, possibly due to leaching, but is instead dominated by amino acid derived products present possibly as (degraded) polypeptides.

6. The pyrolysates of the mineral soil samples with a higher $\mathrm{pH}$ yield a distribution of products similar to that found in the bottom layer of the low $\mathrm{pH}$ samples, but with some evidence of lignin.

Thus, we can demonstrate that soil $\mathrm{pH}$ has a substantial effect on the preservation of higher plant derived molecules. Soils with a low $\mathrm{pH}$ appear to preserve biomolecules by retarding the activities of micro-organisms.

Acknowledgements - This project was undertaken whilst RPE was in receipt of a NERC Grant GR3/9578. J. Carter and A. Gledhill are thanked for their help with the GC-MS and GCC-IRMS analyses. The use of the NERC Mass Spectrometry Facilities (Grants GR3/2951, GR3/ 3758, FG6/36/01) is gratefully acknowledged. IACR receives grant-aided support from the BBSRC. S. J. Everington is thanked for her help in the preparation of samples.

\section{REFERENCES}

Amblès, A., Magnoux, P., Jambu, P., Jacquesy, R. and Fustec, E. (1989) Effects of addition of bentonite on the hydrocarbon fraction of a podzol ( $\mathrm{A}_{1}$ Horizon). Journal of Soil Science 40, 685-694.

Amblès, A., Jambu, P., Jacquesy, J.-C., Parlanti, E. and Secouet, B. (1993) Changes in the ketone portion of lipid components during the decomposition of plant debris in a hydromorphic forest-podzol. Soil Science 156, 49-56. 
Amblès, A., Jambu, P., Parlanti, E., Joffre, J. and Riffe, C. (1994) Incorporation of natural monoacids from plant residues into an hydromorphic forest podzol. European Journal of Soil Science 45, 175-182.

Avery, B. W. and Catt, J. A. (1995) The Soil at Rothamsted. Lawes Agricultural Trust, IACRRothamsted, Harpenden.

Augris, N., Balesdent, J., Mariotti, A., Derenne, S. and Largeau, C. (1998) Structure and origin of insoluble and nonhydrolyzable, aliphatic oragnic matter in a forest soil. Organic Geochemistry 28, 119-124.

van Bergen, P. F., Bull, I. D., Poulton, P. R. and Evershed, R. P. (1997a) Organic geochemical studies of soils from the Rothamsted classical experiments: I total lipid extracts, solvent insoluble residues and humic acids from Broadbalk Wilderness. Organic Geochemistry 26, 117-135.

van Bergen, P. F., Bland, H. A., Horton, M. C. and Evershed, R. P. (1997b) Chemical and morphological changes in archaeological seeds and fruits during preservation by desiccation. Geochimica Cosmochimica Acta 61, 1919-1930.

van Bergen, P. F., Flannery, M. B., Poulton, P. R. and Evershed, R. P. (1998) Organic geochemical studies of soils from Rothamsted Experimental Station. III Nitrogen-containing macromolecular moieties in soil organic matter from Geescroft Wilderness. In Nitrogencontaining Macromolecules in the Bio- and Geosphere, ed. B. A. Stankiewicz and P. F. van Bergen. ACS Symposium Series, 707. American Chemical Society, Washington, DC (in press).

Bracewell, J. M. and Robertson, G. W. (1984) Quantitative comparison of the nitrogen-containing pyrolysis products and amino acid composition of soil humic acids. Journal of Analytical Applied Pyrolysis 6, 19-29.

Bull, I. D., van Bergen, P. F., Poulton, P. R. and Evershed, R. P. (1998) Organic geochemical studies of soils from the Rothamsted classical experiments-II, Soils from the Hoosfield Spring barley experiment treated with different quantities of manure. Organic Geochemistry 28, 11-26.

Collister, J. W., Rieley, G., Stern, B., Eglinton, G. and Fry, B. (1994) Compound specific $\delta^{13} \mathrm{C}$ analyses of leaf lipids from plants with differing carbon dioxide metabolisms. Organic Geochemistry 21, 619-627.

Coûteaux, M.-M., Bottner, P. and Berg, B. (1995) Litter decomposition climate and litter quality. Trends in Evolution and Ecologie 10, 63-66.

F.A.O. (1990) F.A.O.-UNESCO soil map of the world: revised legend. World soil resources report 60 . Rome.

Guggenberger, G., Christensen, B. T. and Zech, W. (1994) Land-use effects on the composition of organic matter in particle-size separates of soils. I. Lignin and carbohydrate signature. European Journal of Soil Science 45, $449-458$.

Guggenberger, G., Zech, W., Haumaier, L. and Christensen, B. T. (1995) Land-use effects on the composition of organic matter in particle-size separates of soils. II. CPMAS and solution ${ }^{13} \mathrm{C}$ NMR analysis. European Journal of Soil Science 46, 147-158.

Hardon, H. J. (1936) Factoren, die het organische stof en het stikstof-gehalte van tropische gronden beheerschen. Landbouw XI(12), 517-540.

Huang, Y., Eglinton, G., van der Hage, E. R. E., Boon, J. J., Bol, R. and Ineson, P. (1998) Dissolved organic matter and its parent organic matter in grass upland soil horizons studied by analytical pyrolysis techniques. European Journal of Soil Science 49, 1-15.

Jenkinson, D. S., Harkness, D. D., Vance, E. D., Adams, D. E. and Harrison, A. F. (1992) Calculating net primary production and annual input to soil from the amount and radiocarbon content of soil organic matter. Soil Biology \& Biochemistry 24, 295-308.

Johnston, A. E., Goulding, K. W. T. and Poulton, P. R. (1986) Soil acidification during more than 100 years under permanent grassland and woodland at Rothamsted. Soil Use and Management 2, 3-10.

Jones, D. M., Carter, J. F., Eglinton, G., Jumeau, E. J. and Fenwick, C. S. (1991) Determination of $\delta^{13} \mathrm{C}$ values of straight chain and cyclic alcohols by gas chromatography isotope ratio mass spectrometry. Biological Mass Spectrometry 20, 641-646.

Kögel-Knabner, I. (1992) Forest soil organic matter: structure and formation. Bayreuther Bodenkundliche Berichte 24, 103p.

Lichtfouse, E., Dou, S., Girardin, C., Grably, M Balesdent, J., Behar, F. and Vandenbroucke, M. (1995) Unexpected ${ }^{13} \mathrm{C}$-enrichment of organic components from wheat crop soils: evidence for the in situ origin of soil organic matter. Organic Geochemistry 23, 865-868.

Lockheart, M. J., van Bergen, P. F and Evershed, R. P. (1997) Variations in the stable carbon isotope compositions of individual lipids observed in the leaves of modern angiosperms: implications for the study of higher land plant derived sedimentary organic matter. Organic Geochemistry 26, 137-153.

Matzke, K. and Riederer, M. (1991) A comparative study into the chemical constitution of cutins and suberins from Picea abies (L.) Karst., Quercus robur L., and Fagus sylvatica L.. Planta 185, 233-245.

Motavalli, P. P., Palm, C. A., Parton, C. A., Elliott, E. T. and Frey, S. D. (1995) Soil $\mathrm{pH}$ and organic C dynamics in tropical forest soils: evidence from laboratory and simulation studies. Soil Biology \& Biochemistry 27, 1589-1599.

Moucawi, J., Fustec, E. and Jambu, P. (1981) Decomposition of lipids in soils: free and esterified fatty acids, alcohols and ketones. Soil Biology \& Biochemistry 13, 461-468.

Oades, J. M. (1988) The retention of organic matter in soils. Biogeochemistry 5, 35-70.

Paris, R. (1963) The distribution of plant glycosides. In Chemical Plant Taxonomy, ed. T. Swain. Academic Press, London, pp. 337-358.

Paul, E. A. and Clark, F. E. (1996) Soil Microbiology and Biochemistry. Academic Press, San Diego.

Post, W. M., Emanuel, W. R., Zinke, P. J. and Strangenberger, A. G. (1982) Soil carbon pools and world life zones. Nature 298, 156-159.

Riederer, M., Matzke, K., Ziegler, F. and Kögel-Knabner, I. (1993) Occurrence, distribution and fate of the lipid plant biopolymers cutin and suberin in temperate forest soils. Organic Geochemistry 20, 1063-1076.

Saiz-Jimenez, C. and de Leeuw, J. W. (1986) Lignin pyrolysis products: their structures and their significance as biomarkers. In Advances in Organic Geochemistry 1985, ed. D. Leythauser and J. Rullkötter, Organic Geochemistry, 10, 1986, pp. 869-876.

Spain, A. V. (1990) Influence of environmental conditions and some soil chemical properties on the carbon and nitrogen contents of some tropical Australian rainforest soils. Australian Journal of Soil Research 28, 825-839.

Tegelaar, E. W., de Leeuw, J. W. and Saiz-Jimenez, C. (1989) Possible origin of aliphatic moieties in humic substances. Science of the Total Environment 81/82, 117.

Thurston, J. M., Williams, E. D. and Johnston, A E. (1976) Modern developments in an experiment on permanent grassland started in 1856: effects of fertilisers and lime on botanical composition and crop and soil analyses. Annals of Agronony 27, 1043-1082.

Tilman, D., Dodd, M. E., Silvertown, J., Poulton, P. R. Johnston, A. E. and Crawley, M. J. (1994) The Park 
Grass experiment: insights from the most long-term ecological study. In Long-term Experiments in Agricultural and Ecological Sciences, ed. R. A. Leigh and A. E. Johnston. CAB International, Wallingford, pp 287-303.

Tulloch, A. P. (1976) Chemistry of waxes of higher plants. In Chemistry and Biochemistry of Natural Waxes, ed. P. E. Kolattukudy. Elsevier, Amsterdam, pp 236-287.

U.S.D.A. (1992) Soil Survey Staff. Key to soil taxonomy. SMSS Technical monograph No. 19, 5th edn., Pocahontas Press, Blacksburg, VA.
Walton, T. J. (1990) Waxes, cutin and suberin. In Methods in Plant Biochemistry, ed. J. L. Harwood and J. R. Bowyer. Academic Press, London, pp 105-158.

Weete, J. D. (1976) Algal and fungal waxes. In Chemistry and Biochemistry of Natural Waxes, ed. P. E. Kolattukudy. Elsevier, Amsterdam, pp 349-418.

Yamamoto, Y. (1995) Allelopathic potential of Anthoxanthum odoratum for invading Zoysia grassland in Japan. Journal of Chemical Ecology 21, 1365-1373. 